\title{
BRPKM
}

Buletin Riset Psikologi dan Kesehatan Mental

http://e-journal.unair.ac.id/index.php/BRPKM

e-ISSN : 2776-1851

ARTIKEL PENELITIAN

\section{Hubungan antara Social Support dengan Career Adaptability pada Mahasiswa Tingkat Akhir}

\author{
ISMALIA NURUL A. H. \& FENDY SUHARIADI* \\ Fakultas Psikologi Universitas Airlangga
}

\begin{abstract}
ABSTRAK
Tujuan penelitian ini untuk mengetahui adanya hubungan antara social support dengan career adaptability. Metode penelitian yang digunakan pada penelitian ini adalah pendekatan kuantitatif eksplanatif dengan metode pengumpulan data berupa survei. Alat ukur yang digunakan untuk mengukur variabel dukungan sosial adalah Interpersonal Support Evaluation Scale - 12 (ISEL-12), dimana alat ukur tersebut berbentuk skala likert yang berisi 12 aitem dengan $\alpha=0,820$. Sedangkan alat ukur yang digunakan untuk mengukur variabel adaptabilitas karier adalah Career Adapt-Abilities Scale, dimana alat ukur tersebut berbentuk skala likert yang berisi 24 aitem dengan $\alpha=0,926$. Partisipan pada penelitian ini sebanyak 173 mahasiswa tingkat akhir dimana sedang menempuh minimal semester 8 untuk jenjang D4/S1 dan minimal semester 6 untuk jenjang D3. Teknik korelasi yang digunakan adalah teknik non-parametrik Spearman`s Rho menggunakan program IBM SPSS Statistic 22. Hasil analisis dalam penelitian ini menunjukkan adanya hubungan positif antara social support dengan career adaptability $(\mathrm{r}=0,262 ; \mathrm{p}<0,01)$.
\end{abstract}

Kata kunci: adaptabilitas karier, dukungan sosial, mahasiswa

\section{ABSTRACT}

This study aims to determine the relationship between social support and career adaptability. This study use an explanatory quantitative approach with a survey method. The measuring instrument that is used to measure the social support variable is the Interpersonal Support Evaluation Scale - 12 (ISEL12 with $\alpha=0,820$. Meanwhile, the measuring instrument that is used to measure the career adaptability variable is the Career Adapt-Abilities Scale with $\alpha=0,926$. Participants in this study were 173 final year students who were taking at least 8th semester for D4/S1 level and at least 6th semester for D3 level. The correlation technique that was used in this research is Spearman's Rho non-parametric technique using the IBM SPSS Statistic 22 program. The results of the analysis in this study indicate a positive relationship between social support and career adaptability $(r=0,262 ; p<0,01)$.

Keywords: career adaptability, college student, social support

Buletin Penelitian Psikologi dan Kesehatan Mental (BRPKM), tahun, Vol. 1(2), 1444-1450

*Alamat korespondensi: Fakultas Psikologi Universitas Airlangga, Kampus B Universitas Airlangga Jalan Airlangga 4-6 Surabaya 60286. Surel: fendy.suhariadi@psikologi.unair.ac.id

Naskah ini merupakan naskah dengan akses terbuka dibawah ketentuan the Creative Common Attribution License (CC-BY-4.0) (http://creativecommons.org/licenses/by/4.0), 
sehingga penggunaan, distribusi, reproduksi dalam media apapun atas artikel ini tidak dibatasi, selama sumber aslinya disitir dengan baik.

\section{PENDAHULUAN}

Pada umumnya individu yang berada pada usia dewasa awal yaitu mulai usia 18 tahun sampai 22 tahun telah menyelesaikan masa pendidikannya dan bersiap untuk terjun ke dunia kerja. Selama masa itu, mereka mulai melakukan eksplorasi diri untuk mencari jalur karier yang ingin dicapai, serta mengambil sebuah keputusan tentang pekerjaan yang ingin ditekuni. Hal tersebut didukung oleh Santrock yang menyatakan bahwa individu dengan usia sekitar dua puluhan sampai akhir masa dewasa awal mulai menelusuri karier yang sesuai dengan bidangnya (Santrock, 2013). Individu pada masa dewasa awal juga biasanya dicirikan dengan memiliki pekerjaan tetap atau mandiri secara ekonomi. Kemandirian secara ekonomi sendiri termasuk salah satu hal yang menjadi proses menuju kedewasaan diri dan tentunya individu akan melalui proses yang cukup panjang untuk mewujudkannya. Transisi ke dunia kerja merupakan proses yang signifikan dan seringkali sulit dihadapi oleh mahasiswa. Kesulitan tersebut dapat memberikan dampak berupa tingginya tingkat pergantian pekerjaan (turnover) di antara lulusan baru (Wendlandt \& Rochlen, 2008). Selain itu, mahasiswa yang sedang mengalami transisi masih belum memikirkan pekerjaan apa yang akan dimiliki, rendahnya mahasiswa yang berwirausaha dan kurangnya persiapan terhadap hal yang mungkin terjadi setelah lulus dari perkuliahan (Azhar \& Aprilia, 2018). Kondisi tersebut menuntut mahasiswa agar sedini mungkin memulai persiapan dan meningkatkan kemampuan penyesuaian dirinya dalam menghadapi transisi peran dari pelajar menjadi pekerja.

Perubahan yang terjadi baik itu dari bidang ekonomi maupun industri mengakibatkan adanya peningkatan kebutuhan angkatan kerja yang berkualitas dan terampil dalam bidangnya. Individu juga perlu memiliki ketahanan mental yang baik agar mudah beradaptasi dengan lingkungan kerjanya (Rosulin \& Paramita, 2016). Tingginya kebutuhan angkatan kerja yang berkualitas dan mumpuni membuat mahasiswa harus terus berusaha untuk mempersiapkan diri ketika terjun dalam dunia kerja. Namun dalam hal mempersiapkan diri tentunya bukanlah suatu usaha yang mudah.

Pentingnya career adaptability dalam transisi karier telah dibuktikan oleh beberapa penelitian. Career adaptability merupakan kemampuan individu yang dapat digunakan dalam menghadapi perubahan situasi yang menekan. Hal itu telah dibuktikan oleh studi penelitian Koen dkk (2012) yang menyatakan bahwa career adaptability dapat membantu mahasiswa di Belanda dalam memilih dan menentukan pekerjaan yang sesuai. Melalui penelitian tersebut juga menunjukkan bahwa career adaptability mampu membantu mahasiswa dalam mempersiapkan diri untuk mengatur strategi dalam menghadapi transisi dunia kerja. Lalu mahasiswa yang telah lulus atau fresh graduate akan membutuhkan waktu lebih lama daripada pencari kerja biasa untuk mendapatkan pekerjaan yang sesuai serta memiliki peluang lebih besar untuk mendapatkan ketidaksesuaian bidang kerja dan hal tersebut tentu akan menimbulkan masalah yaitu pengangguran (Koen dkk., 2012). Lalu penelitian oleh Young menunjukkan bahwa dengan terlalu lama mencari kerja mengakibatkan para pencari kerja akan menyerah dalam persaingan kerja (Young, 2012). Sejalan dengan penelitian, Hou, Wu, \& Liu yang memaparkan bahwa fresh graduate membutuhkan rentan waktu lebih lama untuk mendapatkan pekerjaan yang sesuai dengan bidangnya, sehingga penting bagi mahasiswa untuk berupaya mengembangkan kemampuan career adaptability agar mampu beradaptasi dalam transisi karier (Hou dkk., 2014). Selain itu, jika kemampuan mahasiswa dalam menghadapi transisi pasca lulus perguruan tinggi tidak optimal maka akan mengakibatkan mahasiswa sulit untuk mendapatkan pekerjaan (Konstam dkk., 2015). 
Career adaptability dipengaruhi oleh berbagai faktor. Patton \& Lokan menyebutkan beberapa faktor yang mempengaruhi career adaptability antara lain usia, jenis kelamin, status sosial dan ekonomi, tingkat pendidikan, serta pengalaman kerja (Patton \& Lokan, 2001). Lalu penelitian Kracke menunjukkan faktor yang dapat mempengaruhi career adaptability antara lain attachment orang tua dan teman sebaya (Kracke, 2002). Selanjutnya, hasil penelitian Othman menunjukkan bahwa resiliensi, optimisme, dan harapan dapat mempengaruhi tingkat career adaptability (Othman dkk., 2018). Dan hasil penelitian Oztemel dan Akyol menyatakan bahwa adanya hubungan yang signifikan antara happiness (kebahagiaan), future perspective (perspektif masa depan), dan social support (dukungan sosial) dengan career adaptability (adaptabilitas karier) pada mahasiswa di Turki (Öztemel \& YıldızAkyol, 2019).

Career adaptability adalah suatu kemampuan yang dimiliki oleh individu guna mempersiapkan dirinya dalam menyesuaikan diri pada berbagai permasalahan dan situasi yang akan terjadi di lingkungan kerja, baik itu hal yang dapat diantisipasi maupun hal yang tidak dapat diantisipasi (Savickas \& Porfeli, 2012). Sedangkan Social support mengacu pada berbagai sumber daya yang disediakan oleh ikatan interpersonal seseorang, dimana terkait dengan persepsi ketersediaan empat fungsi dukungan yang berbeda (Cohen dkk., 1985).

Berdasarkan pemaparan diatas, maka hipotesis dalam penelitian ini adalah sebagai berikut:

$H_{0} \quad$ : Tidak terdapat hubungan antara social support dengan career adaptability pada mahasiswa tingkat akhir.

$H_{1} \quad$ : Terdapat hubungan antara social support dengan career adaptability pada mahasiswa tingkat akhir.

\section{METODE}

\section{Desain Penelitian}

Tipe penelitian ini adalah dengan menerapkan tipe penelitian kuantitatif eksplanatif. Pendekatan kuantitatif eksplanatif memfokuskan proses analisis data berupa numerik lalu diolah menggunakan statistik serta untuk mengetahui mengapa sebuah peristiwa terjadi dengan menguraikan ataupun menguji suatu teori (Djamba \&Neuman, 2014). Kemudian metode pengumpulan data yang digunakan adalah metode survei yang dilakukan melalui penyebaran kuesioner yang berisi alat ukur dari variabel penelitian (Djamba \& Neuman, 2014).

\section{Partisipan}

Partisipan dalam penelitian ini adalah mahasiswa tingkat akhir. Dalam pengambilan sampel teknik yang digunakan adalah non-probability dalam bentuk accidental sampling. Accidental sampling didefinisikan sebagai salah satu bentuk pengambilan sampel dimana peneliti memilih siapapun yang ia temui (Djamba \& Neuman, 2014). Dalam menentukan jumlah sampel dalam penelitian, peneliti menggunakan perangkat lunak $\mathrm{G}^{*}$ Power dengan menggunakan pengaturan statistical test berupa correlation: bivariate normal model dengan correlation sebesar 0,3, alpha 0,05, dan power 0,8 yang menghasilkan total sampel yang dibutuhkan sebanyak 153 orang. Setelah dilakukan pengambilan data, partisipan yang diperoleh sebanyak 173 orang. $\left(M_{u s i a}=21,88 ; S D_{u s i a}=0,88 ; 70\right.$ persen perempuan; 30 persen laki-laki).

\section{Pengukuran}

Untuk mengukur kedua variabel pada penelitian ini, jenis alat ukur yang digunakan berupa skala likert. Skala pertama untuk mengukur variabel bebas yaitu Social Support pada penelitian ini adalah versi 
singkat dari Interpersonal Support Evaluation List (ISEL); ISEL-12 (Cohen dkk., 1985) yang berisi 12 aitem dan 4 pilihan jawaban dari 1 sampai dengan 4 dengan $\alpha=0,820$. Skala kedua untuk mengukur variabel terikat yaitu Career Adaptability pada penelitian ini adalah Career Adapt Abilities Scale (CAAS)Indonesian Form yang diadaptasi berdasarkan CAAS International Form 2.0 (Savickas \& Porfeli, 2012) oleh Sulistiani (Sulistiani dkk., 2019). Alat ukur tersebut berisi 24 aitem dan 5 pilihan jawaban dari 1 sampai dengan 5 dengan $\alpha=0,926$.

\section{Analisis Data}

Teknik analisis yang digunakan antara lain uji asumsi dan uji korelasi. Uji asumsi yang digunakan pada penelitian ini adalah uji normalitas dan uji linearitas serta uji korelasi yang digunakan adalah korelasi Spearman's Rho. Selanjutnya, pengolahan data yang dilakukan menggunakan program IBM SPSS Statistic 22 for Windows.

\section{HASIL PENELITIAN}

Berdasarkan analisis deskriptif pada data yang diperoleh menunjukkan bahwa partisipan memiliki tingkat career adaptability kategori tinggi berjumlah 32 partisipan $(18,5 \%)$, kategori sedang atau ratarata berjumlah 115 partisipan (66,5\%), dan kategori rendah atau dibawah rata-rata berjumlah 26 partisipan (15\%). Kemudian social support dengan kategori tinggi berjumlah 27 partisipan (15,6\%), kategori sedang berjumlah 113 partisipan (65,3\%), dan kategori rendah berjumlah 33 partisipan (19\%).

Selanjutnya berdasarkan uji korelasi Spearman's Rho menunjukkan hasil bahwa social support berkorelasi positif dengan kategori rendah $(r(173)=0,262 ; p<0,01)$ dengan career adaptability.

\section{DISKUSI}

Penelitian ini bertujuan untuk menjawab pertanyaan tentang ada atau tidaknya hubungan antara social support dengan career adaptability. Dalam menjawab pertanyaan penelitian tersebut, peneliti melakukan beberapa macam uji asumsi. Hasil dari uji asumsi membuktikan bahwa data yang diperoleh bersifat normal dan linear. Lalu berdasarkan hasil uji korelasi $(r=0,262)$ dapat ditarik kesimpulan bahwa terdapat hubungan positif antara kedua variabel yang diteliti. Arah hubungan yang positif dapat diartikan ketika social support meningkat maka career adaptability seseorang juga akan meningkat. Berlaku juga sebaliknya, apabila social support menurun, maka career adaptability seseorang juga ikut menurun. Hasil data yang telah diinterpretasi menunjukkan bahwa mahasiswa tingkat akhir memiliki tingkat social support dan career adaptability yang berada pada taraf rendah.

Hasil penelitian ini sejalan dengan penelitian-penelitian sebelumnya. Menurut Wang \& Fu pada penelitiannya memaparkan bahwa social support dengan career adaptability memiliki hubungan yang signifikan (Wang \& Fu, 2015). Pada penelitian tersebut menjelaskan bahwa social support dapat membantu individu dalam menghadapi lingkungan kerja yang kompetitif. Lalu hasil penelitian oleh Karacan, Ozdemir \& Guneri menunjukkan bahwa adanya hubungan yang signifikan antara social support dengan career adaptability dimana individu yang lebih banyak menerima dukungan sosial dari berbagai sumber seperti dari orang tua, kerabat atau teman sebaya, dan orang terdekat lainnya akan memiliki tingkat career adaptability yang tinggi (Karacan-Özdemir, 2016). Selain itu penelitian Oztemel \& Akyol menyatakan bahwa adanya hubungan antara social support dengan career adaptability yang ditandai dengan social support mampu membantu individu merasa dirinya dicintai maupun diapresiasi serta secara bersamaan mampu merawat kondisi mental individu antara lain mengurangi dampak negatif 
yang timbul dan membantu individu dalam menyesuaikan dirinya dengan perubahan yang sedang dihadapi (Öztemel \& Yıldız-Akyol, 2019).

\section{SIMPULAN}

Berdasarkan hasil analisis data dan pembahasan yang telah dilakukan dapat disimpulkan bahwa mengenai hipotesis penelitian, $H_{0}$ ditolak dan $H_{a}$ dapat diterima yang berarti terdapat hubungan antara social support dengan career adaptability pada mahasiswa tingkat akhir dengan kekuatan hubungan yang rendah dan positif. Arah hubungan yang positif dapat diartikan ketika social support meningkat maka career adaptability seseorang juga akan meningkat. Berlaku juga sebaliknya, apabila social support menurun, maka career adaptability seseorang juga ikut menurun.

Saran untuk penelitian selanjutnya dapat menggunakan subjek dengan jumlah yang lebih banyak serta mewakili berbagai daerah di Indonesia, mengingat subjek dalam penelitian ini hanya mewakili beberapa daerah yang didominasi oleh daerah sekitar tempat tinggal peneliti yaitu daerah Jawa. Saran bagi mahasiswa khususnya yang telah berada di tingkat akhir, career adaptability merupakan kemampuan yang perlu dimiliki oleh mahasiswa terutama saat menghadapi masa transisi dimana mahasiswa akan mengalami perubahan peran menjadi pekerja. Untuk itu, mahasiswa perlu mempersiapkan diri sebaik dan sedini mungkin dalam merencanakan dan menentukan karier yang akan dilakukan setelah lulus nanti. Persiapan yang dapat dilakukan mahasiswa antara lain mengeksplorasi karier apa yang sesuai seperti mengikuti magang dan juga aktif memperluas relasi sosial dengan mengikuti kegiatan berorganisasi. Kemudian mahasiswa juga dapat mencari berbagai bentuk dukungan sosial seperti dukungan emosional maupun instrumental yang berasal dari orang terdekat di sekitarnya seperti keluarga, teman sebaya, mentor dalam melewati masa transisi hidupnya guna mengurangi timbulnya dampak negatif selama menghadapi perubahan yang sedang dihadapi sehingga mahasiswa dapat beradaptasi dengan baik pada lingkungan yang baru yaitu lingkungan kerja.

\section{UCAPAN TERIMAKASIH}

Terima kasih yang sebesar-besarnya penulis panjatkankepada Allah SWT yang senantiasa menjadi tempat untuk memanjatkan doa, orang tua yang selalu memberikan berbagai bentuk dukungan yang dibutuhkan, teman-teman, partisipan penelitian, dan seluruh pihak yang telah membantu peneliti dalam proses penelitian ini. Semoga selalu diberikan nikmat, kesehatan dan kelancaran dalam hidup.

\section{DEKLARASI POTENSI TERJADINYA KONFLIK KEPENTINGAN}

Ismalia Nurul dan Fendy Suhariadi sama sekali tidak melakukan kerja sama sebagai konsultan atau adanya kepemilikan saham, atau menerima dana apapun baik dari perusahaan, organisasi maupun pihak lain yang akan mengambil keuntungan dari penerbitan naskah ini.

\section{PUSTAKA ACUAN}

Azhar, R., \& Aprilia, E. D. (2018). Hubungan Antara Kecerdasan Emosi Dan Adaptabilitas Karir Pada Sarjana Di Banda Aceh. Journal of Psychological Science and Profession, 2(2), 173. https://doi.org/10.24198/jpsp.v2i2.17691 
Cohen, S., Mermelstein, R., Kamarck, T., \& Hoberman, H. M. (1985). Measuring The Functional Components of Social Support: Theory, Research and Applications. Social Support: Theory, Research and Applications, 24, 73-94.

Hou, C., Wu, L., \& Liu, Z. (2014). Effect of Proactive Personality and Decision-Making Self-Efficacy on Career Adaptability Among Chinese Graduates. Social Behavior and Personality: An International Journal, 42(6), 903-912. https://doi.org/10.2224/sbp.2014.42.6.903

Karacan-Özdemir, N. (2016). The Factors contribute to career adaptability of high school students [Ph.D. - Doctoral Program]. Middle East Technical University.

Koen, J., Klehe, U. C., \& Van Vianen, A. E. M. (2012). Training career adaptability to facilitate a successful school-to-work transition. Journal of Vocational Behavior, 81(3), 395-408. https://doi.org/10.1016/j.jvb.2012.10.003

Konstam, V., Celen-Demirtas, S., Tomek, S., \& Sweeney, K. (2015). Career Adaptability and Subjective Well-Being in Unemployed Emerging Adults: A Promising and Cautionary Tale. Journal of Career Development, 42(6), 463-477. https://doi.org/10.1177/0894845315575151

Kracke, B. (2002). The role of personality, parents and peers in adolescents career exploration. Journal of Adolescence, 25(1), 19-30. https://doi.org/10.1006/jado.2001.0446

Djamba, Y. K., \& Neuman, W. L. (2002). Social research methods: Qualitative and quantitative approaches. Teaching Sociology, 30(3), 380.

Othman, R., Kamal, N. M., Alias, N. E., Ismail, S., \& Sahiq, A. N. M. (2018). Positive Psychological Traits and Career Adaptability among Millennials. International Journal of Academic Research in Business and Social Sciences, 8(9), 1420-1433. https://doi.org/10.6007/ijarbss/v8-i9/4706

Öztemel, K., \& Yıldız-Akyol, E. (2019). The Predictive Role of Happiness, Social Support, and Future Time Orientation in Career Adaptability. Journal of Career Development, 48(3), 199-212. https://doi.org/10.1177/0894845319840437

Patton, W., \& Lokan, J. (2001). Perspectives on Donald Super's Construct of Career Maturity. International Journal for Educational and Vocational Guidance, 1, 31-48. https://doi.org/10.1023/A:1016964629452

Rosulin, R., \& Paramita, P. P. (2016). Hubungan antara Hardiness dengan Adaptabilitas Karir pada Siswa SMK Kelas XII. Jurnal Psikologi Pendidikan Dan Perkembangan, 5(1).

Santrock, J. W. (2013). Life-span development. McGraw-Hill Create

Savickas, M. L., \& Porfeli, E. J. (2012). Career Adapt-Abilities Scale: Construction, reliability, and measurement equivalence across 13 countries. Journal of Vocational Behavior, 80(3), 661-673. https://doi.org/10.1016/j.jvb.2012.01.011

Sulistiani, W., Suminar, D. R., \& Hendriani, W. (2019). The Career Adapt-Abilities Scale-Indonesian Form: Psychometric Properties and Construct Validity. Proceeding of the 4 th International Conference on Education. https://doi.org/10.17501/24246700.2018.4201

Wang, Z., \& Fu, Y. (2015). Social support, social comparison, and career adaptability: A moderated mediation model. Social Behavior and Personality, 43(4), 649-659.

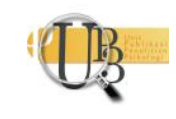


https://doi.org/10.2224/sbp.2015.43.4.649

Wendlandt, N. M., \& Rochlen, A. B. (2008). Addressing the college-to-Work transition: Implications for university career counselors. Journal of Career Development, 35(2), 151-165. https://doi.org/10.1177/0894845308325646

Young, C. (2012). Unemployment Insurance and Job Search Effort: Evidence from Random Audits. Manuscript, Stanford University. 1-30. 